\title{
VORWORT ZUR 2. UND 3. AUFLAGE
}

Dieses Buch ist von slawistischer und pädagogischer Seite gut aufgenommen worden. Für die in Rezensionen ${ }^{1}$ und Briefen vorgetragenen kritischen Bemerkungen, Wünsche und Verbesserungsvorschläge möchte ich allen meinen herzlichen Dank aussprechen. Freilich konnte ich nicht jeden Wunsch berücksichtigen: manches entsprach nicht dem Rahmen und den Zielen des Buches; die Ausarbeitung des so wünschenswerten - und im Vorwort zur 1. Auflage für eine spätere Auflage in Aussicht gestellten - Kapitels über den Akzent war mir aus Zeitmangel nicht möglich; manche Bemerkungen scheinen mir nicht richtig zu sein.

Weitere Anderungen wurden durch die in den letzten Jahren in der Sowjetunion erschienene orthoepische Literatur hervorgerufen, insbesonder durch zwei Arbeiten: 1954 erschien von Р. И. Аванесов, Русское литературное произношение, eine zweite verbesserte Auflage; 1955 wurde vom Institut für Sprachwissenschaft der Akademie der Wissenschaften der UdSSR, unter der gemeinsamen Redaktion von Р. И. Аванесов und С. И. Ожегов, ein Hand- und Wörterbuch zum Akzent und zur Aussprache der russischen Literatursprache (Русское литературное ударение и произношение) herausgegeben, das einen offiziösen Charakter trägt. Ich habe alle in meiner Darstellung angeführten Regeln und Beispiele an Hand dieser beiden sowjetischen Arbeiten neu überprüft - wobei mich dankenswerterweise Dr. Helger Vogt unterstützte - und an den entsprechenden Stellen die nötigen Korrekturen vorgenommen, so daß die Arbeit den Stand von 1955 vertritt.

Berlin, 31. Dezember 1956

W. Steinitz

1 Russischunterricht. 1953, S. 534-538 (N. Nikolajew). - Zeitschrift für Phonetik u. allgemeine Sprachwissenschaft, Bd. 8, S. 411-416 (A. Isacenko). - The Slavonic Review, Bd. 33, 1954, S. 236-239 (W. K. Matthews). - Wiener Slavist. Jahrbuch, Bd. 4. 1955, S. 186-188 (W. Appel). - Bulletin de la Socióté de Linguistique de Paris, Bd. 51, 1955, S. 125 (R. L'Hermitte). - Rezensionen der 2. neu. bearbeiteten Auflage: The Slavonic Review, Bd. 36, 1958, S. 585 (W. K. Mathews). Wiener Slavist. Jahrbuch, Bd. 7, 1958, S. 182-183 (H. Galton). 